\title{
How sociable? An exploratory study of university brand visibility in social media
}

\author{
E. Botha* \\ School of Management Studies, University of Cape Town, \\ Private Bag, Rondebosch 7701, Republic of South Africa \\ Elsamari.Botha@uct.ac.za \\ M. Farshid \\ Division of Industrial Marketing, eCommerce and \\ Logistics, Lulea University of Technology, Lulea, Sweden \\ L. Pitt \\ Segal Graduate School of Business, Simon Fraser University \\ Vancouver, Canada \\ Received April 2010
}

\begin{abstract}
Social media has changed both the way in which organizations and their brands interact with their customers and the way in which business gets done. Brands are attempting to utilize social media to reach existing customers, gain new ones and build or maintain credibility and reputation. More importantly, brands need to measure their visibility in the most popular social media relative to that of competitors. This study describes a tool for collecting brand visibility information by looking at the visibility of various South African university brands and their relative positioning from a social media perspective. Correspondence analysis is then used to portray the various university brands in a multi-dimensional space so that they can be contrasted with each other in terms of their visibility in social media. The findings indicate that South African university brands are not distinctly positioned in social media and that none of them seems to currently have a concerted strategy for engaging its stakeholders in a particular social media. This means that there are both opportunities for those who manage these brands, and also threats to these institutions for taking a laissez fair attitude to social media in these times when social media are coming to dominate the Internet in particular and media in general.
\end{abstract}

*To whom all correspondence should be addressed.

\section{Introduction}

Two important milestones were reached in the beginning of 2010. First, the video hosting site YouTube announced that every minute, 24 hours of video content were uploaded to its servers (cf. http://youtube-global.blogspot.com/). Second, the social network platform Facebook was not only larger in terms of population than most of the world's nations, by early 2010 it was second only to the search engine Google in number of daily hits, and users spent much more time on it. Generation Y (those born in 1976 and up to 1999) is now using Facebook as an alternative to email. In February 2010, while Google got 154 million people for an hour, according to A.C. Nielsen research, 118 million people spent 6.5 hours each on Facebook (Arington, 2010), making Facebook a much "stickier" (i.e., where people spent the most time) site than Google.

Social media are now as influential, if not more so than, conventional media. This has a massive impact on brands, as witnessed in recent times by Unilever's Dove "Real Beauty" campaign (Deighton, 2008), and the Greenpeace versus Nestle Kit Kat Palm Oil debacle. While an understanding of social media is obviously important to brands and those who manage them, some key questions remain unanswered, both from the perspective of those who study brands (brand management scholars) those who direct their fortunes (brand managers). These would include questions such as: How do we find out what is being said about a brand in social media? What is being said about competitor brands, and how is that different from our brand? Is our brand more visible in some social media than others, and how does that differ to our competitors? Anyone with knowledge and experience of social media would know that this is difficult enough to achieve on one social medium - it requires a regular tracking of what is being said - spending time on Facebook, or following Twitter tweets. Answering the question becomes even more difficult when one realizes that there is a plethora of social media out there, all of which may be communicating about a particular brand to a greater or lesser extent.

These are the issues we address in this paper. We proceed as follows: First, we provide a brief general overview of the social media phenomenon, and distinguish between the various types of social media. Second, we describe a tool for simultaneously collecting brand visibility information, called How Sociable. Then we briefly describe a study of 
the relative positioning of a number of South African university brands based on data from How Sociable. We explain the use of correspondence analysis to simultaneously portray the various university brands in multi-dimensional space, so that they can be contrasted with each other in terms of their visibility in social media. We also comment on the current state of positioning of these brands in social media. The paper concludes with an acknowledgement of the limitations of the approach followed here, an outlining of the implications for brand managers, and an identification of avenues for future research in this domain.

\section{Social media: A brief overview}

Social media may be defined as media designed to be disseminated through social interaction between individuals and entities such as organizations. Typically it is created using highly accessible (easy to get to) and scalable (can be used to reach large numbers) publishing techniques (Brogan, 2010; Zarella, 2010). Social media uses Internet and webbased technologies to transform broadcast media monologues (one to many) into social media dialogues (many to many). It supports the democratization of knowledge and information, transforming individuals from mere content consumers into content producers. Kaplan and Haenlein (2010) describe social media as "a group of Internet-based applications that build on the ideological and technological foundations of Web 2.0, and that allow the creation and exchange of user-generated content". Businesses and practitioners sometimes refer to social media as user-generated content (UGC) or consumer-generated media (CGM), or when consumers create ads about brands they either love or hate as consumer generated advertising (Berthon et al., 2008).

In many ways social media has not only changed the way in which organizations and their brands interact with their customers, it has also changed the way business gets done. Organizations are now not only able to reach customers online and interact with them, they are also able, if this is managed effectively, to become part of customer conversations. Brands are attempting to utilize social media to reach existing customers, gain new ones, and build or maintain credibility and reputation.

Kaplan and Haenlein (2010) distinguish social media as having three components, namely, concept (art, information, or meme); media (physical, electronic, or verbal); and social interface (intimate direct, community engagement, social viral, electronic broadcast or syndication, or other physical media such as print). Social media are all part of the phenomenon known as "Web 2.0". Web 2.0 is probably best viewed as a series of application progressions over Web 1.0, rather than as something new in and of itself. Web 2.0 is the internet's "now" to Web 1.0 as the internet's "then" - it is much more to do with what people are doing with the technology than the technology itself. Rather than merely retrieve information, users now create and consume it, and hence add value to the websites that permit them to do so. These websites usually provide a richer context to users, by means of user-friendly interfaces that encourage and facilitate participation. Tapscott and Williams (2007) contend that the economy of "the new web" depends on mass collaboration, with economic democracy as an outcome. The notion of individuals simultaneously creating value for themselves and others through profound network effects has not gone unnoticed by entrepreneurs - both forprofit business people, and social entrepreneurs, who see the technology as a way of being innovative and proactive.

Because social media are a relatively novel media format, as far as we are aware there is no readily accepted classification or categorization scheme that exists to distinguish them. In what follows, we briefly describe some of the major types of social media, but do not claim that this is in any sense a definitive or even complete classification as this was not the purpose of the study. We distinguish briefly here between blogs, micro-blogs, social network sites, picture sharing, video sharing, and social news websites.

Blogs (short for "web logs") are websites, owned and written by individuals, who maintain regular commentaries and diaries that may include text, graphics and video, links to other blogs and web pages, usually in reverse chronological order. Rudimentary blogs function simply as personal online diaries, but more sophisticated bloggers concentrate as commentators on a range of focused phenomena, with news and views on particular subjects, covering a wide range of industries, products, services, and special interests. Many blogs permit readers to leave their comments in an interactive format. Some specialized bloggers use their blogs to differentiate themselves from mainstream media; others are like more traditional journalists who see blogs as an alternative or additional communication channel (see Steyn et al., 2008). One of the best known blog hosting sites is Google Blog Posts.

Micro-blogs are social networking services that enable its users to send and read messages very short messages, usually restricted by the number of characters in the message. The best known of these is Twitter, through which users can send messages known as "tweets" - text-based posts of up to 140 characters displayed on the author's profile page and delivered to the author's subscribers who are known as followers. Senders can restrict delivery to those in their circle of friends or, by default, allow open access. Users can send and receive tweets via the Twitter website, text messaging on cell phones, or external applications. Twitter has gained much prominence in the recent past. For example, during the 2009 Victorian bushfires, the Prime Minister of Australia, Kevin Rudd used his Twitter account to send out information on the fires, how to donate money and blood, and where to seek emergency help. In June 2009, following allegations of fraud in the Iranian presidential election, protesters used Twitter as a rallying tool and as a method of communication with the outside world after the government blocked several other modes of communication.

Social networking websites are services on which users can find and add friends and contacts, and send them messages, and update their personal profiles to notify friends, contacts or colleagues about themselves. Additionally, on some social networking websites, users can join networks organized by workplace, school, or college. The best known 
"friendship" social networking sites are Facebook and MySpace, and the best known professional social networking sites are LinkedIn and Plaxo. Facebook currently has more than 400 million active users worldwide (Facebook, 2010).

Picture sharing websites, the best known of which are Flickr, Yahoo Images and Google Images allow users to store and share images.

Video sharing websites allow users to upload and share videos. Typically, unregistered users can watch the videos, while registered users are permitted to upload an unlimited number of videos. The best known of the video sharing websites is YouTube. It was estimated that in 2007 YouTube consumed as much bandwidth as the entire Internet in 2000 (Daily Telegraph, 2008), and by March 2008, YouTube's bandwidth costs were estimated at approximately US\$1 million a day (Fortune, 2008).

Lastly, Social news websites are sites that allow people to discover and share content from anywhere on the Internet, by submitting links and stories, and voting and commenting on submitted links and stories. The best known of these is Digg (www.digg.com).

\section{Gathering brand visibility data in social media: How sociable}

It would be important for those who manage brands to have a good idea of what is being said about these brands in social media, how frequently it is being said, and in what particular media it is being said. This type of data would give the brand manager an indication of the "visibility" of the brand in social media. In most cases, the brand manager would be interested in the social media visibility of their own brand, but would probably also want to make comparisons with the performance of similar or competitive brands. The data could be gathered in one of two ways. First, someone could be given the responsibility of trawling through vast amounts of data in the vast numbers of posts on the various social media platforms and counting and documenting this information. Alternatively, the data could be obtained from a service that regularly trawls through social media electronically, and compiles and counts a brand's visibility. One of these types of service is a website called How Sociable (www howsociable.com).

How Sociable is currently a free service (although a premium, paid-for is envisaged) that tracks the visibility of any brand in 32 different social media, providing a score for the visibility on each, as well as an overall "visibility" score. The software scours the web for all mentions of the sought brand in a wide range of social media, counts these and assigns each mention to the particular social medium it occurred in, in order to achieve counts of the brands mentions across the 32 different social media considered. Simply by entering the brand name into a check box on the website, the user can obtain an overall visibility score and as well as visibility scores across the 32 different social media sites.

The overall visibility score assigned to a brand provides a quick way to compare the visibility of one brand to another. According to the site (Markwell, 2010) a visibility score is calculated by taking a set of benchmark results using one globally recognized traditional brand and giving it a score of 1000. To ensure that even small, local brands will have a chance of scoring, they use a sliding scale. For example, a brand such as Coca-Cola has around 8,000 times more photos mentioning it on the photo sharing site Flickr compared to another brand, but the other brand will still get a score of 10 for having some photos rather than getting 0 .

In Figure 1 below we illustrate the How Social brand visibility scores of 10 different well-known brands recently calculated on How Sociable. For purposes of illustration we chose the five most valuable brands in the world according to the annual Interbrand report on brand values, namely Coca Cola, IBM, Microsoft, GE and Nokia (see www.interbrand.com), and also five well-known social media brands, namely Google, Facebook, Twitter, YouTube and MySpace. All these brands were chosen simply for purposes of illustration, rather than as an endorsement of the Interbrand brand valuation methodology.

\section{Brand visibility}

A few things that are worth noting from Figure 1 include that the most valuable brands are not always the most visible in social media (for example, Coca Cola is less visible than Microsoft); that social media brands, perhaps not unexpectedly are far more visible than the most valuable brands; and, that Facebook is many magnitudes more visible than all other brands.

Before proceeding to a description of the study and it's methodology, it is worth mentioning that How Sociable is just one of a number of tools available to assess brands in social media. For example, Google Analytics is a free service offered by Google that generates detailed statistics about the visitors to a website, which are useful to online marketers. Marketing research companies such as A.C. Neilsen provide a range of paid-for services to their clients that track various aspects of brand visibility in social media. Social Mention (www.socialmention.com) is an interesting (currently free) tool that allows users to assess a brand's real-time status in a wide range of social media, in terms of the brand's strength, sentiments toward it, how passionate those who comment on it are, and the reach it enjoys. However, as far as we are aware, How Sociable is the only free service that allows users to agglomerate a brand's social media awareness across a broad range of the most common social media in a relatively simple and easy to use fashion. 


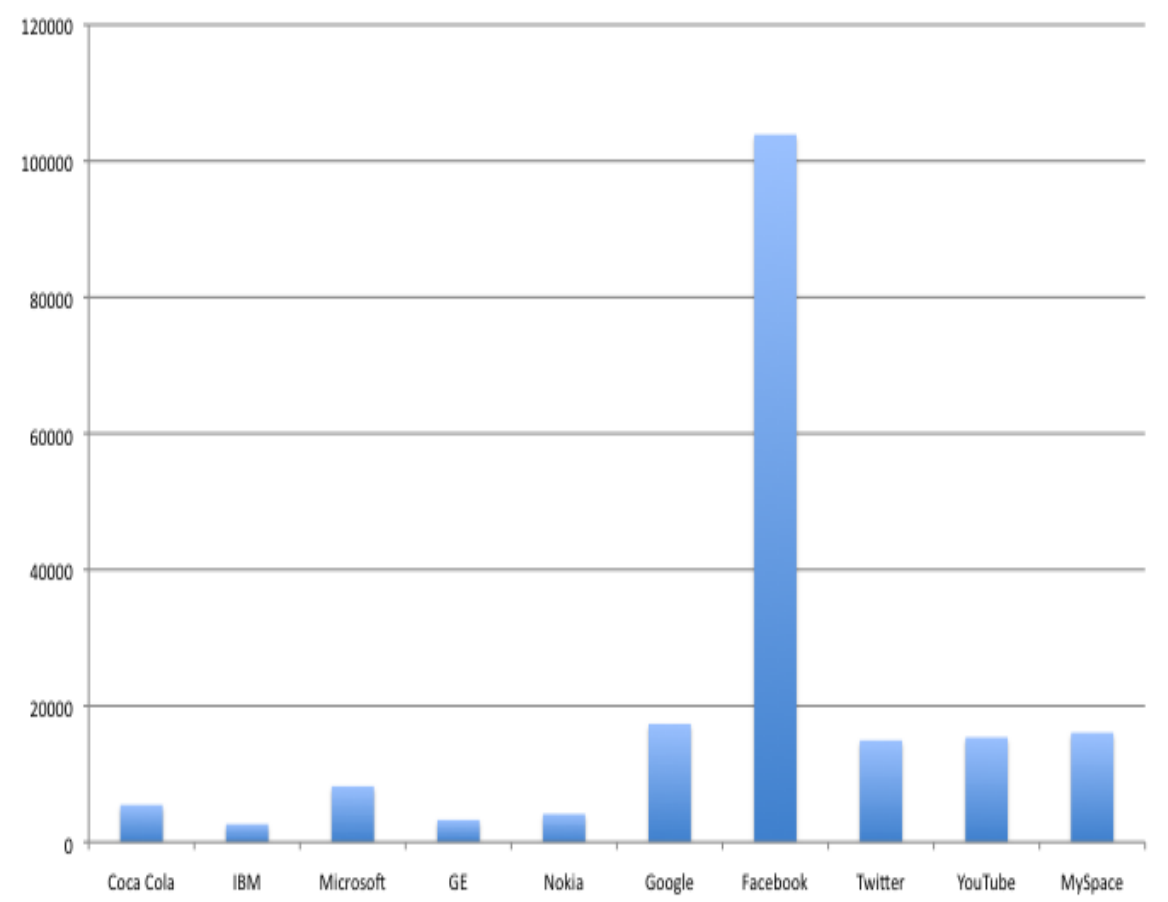

Figure 1: An illustration of brand visibility scores - Most valuable brands and well-known social media brands

\section{The study and methodology}

In order to illustrate our approach to using data from How Sociable to portray similar brands in multi-dimensional space, we gathered data on five South African universities by entering their brand names into the How Sociable website, and having the web site calculate overall visibility scores, as well as visibilities in all 32 social media the site reports on. These five universities were chosen as illustrations because they were the five South African universities with the highest visibility scores, after a previous exercise had entered all South African universities into the How Sociable visibility calculator. These universities were the University of Cape Town, the University of Pretoria, Rhodes University, the University of Stellenbosch and the University of the Witwatersrand (Wits). Next a contingency table was created, with the five universities as columns, and the 32 social media as rows. At this point it was decided to reduce the number of social media to be incorporated into further analysis, for practical reasons. First, for further analysis using correspondence there was a danger that having 32 points on a map would make viewing and interpretation complex and difficult. Second, on quite a few of the less well-known social media, none of the universities were scoring anything at all. Thirteen social media sites were chosen for the final analysis, namely Google Page Score (Google PS), Twitter, MySpace, Ning, Digg, Ecademy, Yahoo Page Score (Yahoo PS), Facebook Groups (Facebook G), Facebook Pages (Facebook P), Google Images (Google I), Xing, Linked In, and YouTube Videos (YouTube V). The contingency table was then used as data input for correspondence analysis using Xlstat.

A summary of the scores for each university brand in each of the selected social media is shown in Table 1 below, and the overall brand visibility scores for each of the universities is shown in Figure 2.

Table 1: Table of the University brands by visibility score in individual social media

\begin{tabular}{|c|c|c|c|c|c|}
\hline & Cape Town & Pretoria & Rhodes & Stellenbosch & Wits \\
\hline Google PS & 74 & 190 & 127 & 113 & 161 \\
\hline Twitter & 174 & 142 & 174 & 265 & 101 \\
\hline MySpace & 40 & 27 & 22 & 24 & 21 \\
\hline Ning & 209 & 166 & 101 & 109 & 335 \\
\hline Digg & 53 & 32 & 23 & 29 & 43 \\
\hline Ecademy & 203 & 176 & 51 & 144 & 125 \\
\hline Yahoo PS & 134 & 111 & 85 & 71 & 42 \\
\hline Facebook G & 837 & 693 & 575 & 394 & 381 \\
\hline Facebook P & 1217 & 1189 & 1355 & 1415 & 1650 \\
\hline Google I & 90 & 78 & 54 & 48 & 59 \\
\hline Xing & 97 & 51 & 44 & 62 & 62 \\
\hline Linked In & 895 & 830 & 475 & 685 & 865 \\
\hline YouTube V & 45 & 41 & 19 & 32 & 21 \\
\hline
\end{tabular}


Two points can be made from the above table and graph. First, interpreting a reasonably complex table such as that in Table 1 can be difficult, as the observer not only wishes to assess where a particular brand is performing well or poorly, but would also want to determine how a brand stacked up to another brand on a particular social medium. Being able to construct a picture in which the brands and the social media where portrayed in two-dimensional space would make this much easier. Second, the graph indicates that the most visible university brand in social media is that of Wits, followed by UCT, Pretoria, Rhodes and Stellenbosch, although none of the five brands is markedly "more visible" than the others. However, what the simple bar graph cannot indicate is what accounts for these scores, and where particular brands might either be performing well or poorly. For that purpose, a two-dimensional map might also be better.

\section{Correspondence analysis}

To identify the associations between the university brands and the social media visibility indicators, we used correspondence analysis. This is a perceptual mapping technique based on cross-tabulation data that is converted into a joint space map by decomposing the $\mathrm{X}^{2}$ statistic of the frequency matrix (Bendixen, 1995, 1996; Greenacre, 1993). The perceptual map created through correspondence analysis is useful in uncovering structural relationships between different variables (Inman et al., 2004) and its graphical nature facilitates interpretation of data that would otherwise be difficult to comprehend (O'Brien, 1993). Moreover, Hair et al. (2006) state that correspondence analysis is best suited for exploratory data analysis, and since our study is exploratory in nature, its use in this type of study is appropriate.

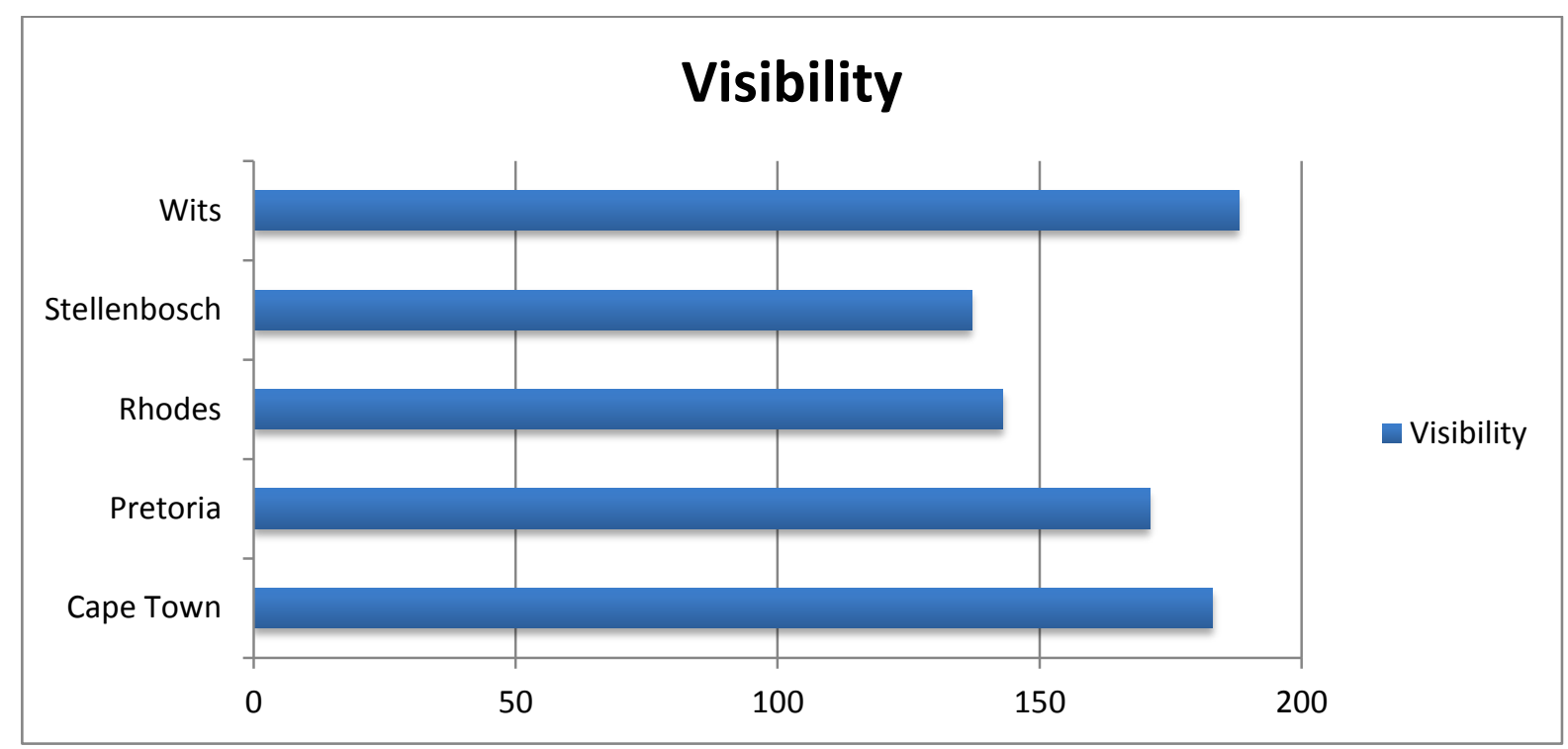

Figure 2: Overall visibility scores of the 5 university brands

\section{The results}

The results of the correspondence analysis are presented in Tables 2 and 3.

Table 2: Test of independence between the rows and the columns

\begin{tabular}{lc}
\hline Chi-square (Observed value) & 932,009 \\
Chi-square (Critical value) & 65,171 \\
DF & 48 \\
p-value & $<0,0001$ \\
Alpha & 0,05 \\
\hline
\end{tabular}

Test interpretation:

H0: The rows and the columns of the table are independent.

Ha: There is a link between the rows and the columns of the table. As the computed p-value is lower than the significance level (alpha $=0,05$ ), the null hypothesis is rejected. The risk to reject the null hypothesis $\mathrm{H} 0$ while it is true is lower than $0,01 \%$.

Ideally for correspondence analysis to proceed, the researcher would prefer to have interdependence between rows and columns. As can be seen from Table 2, the observed $\mathrm{X}^{2}$ is 932, $\mathrm{p}<.0001$, indicating a dependency between the rows and the columns of the contingency table (Bendixen, 1996). In order to determine the dimensionality of a solution, the eigenvalues and the cumulative proportion explained by the dimensions must be examined (Greenacre, 1993; Bendixen, 1995; 1996). Most researchers agree that a two dimensional solution is also preferable due to its ease of display and interpretability (Bendixen, 1995, 1996; Hair et al., 2006; see also Opoku et al., 2007a; 2007b). We therefore chose a two dimensional correspondence plot, which yields a retention of 79.67 percent across the first two dimensions.

An asymmetric plot of the university brands and the social media is shown in Figure 3. An asymmetric plot is used in order that the distance between the row and column points can be interpreted. The plot reveals the underlying structure and positioning of the investigated university brands in relation to the various social media in which they appear. The graphical output also provides information about how the university brands and the social media are positioned vis-a` -vis each other. 
It is apparent from an examination of the brands and their contributions to the dimensions in Table 3, as well as from their positioning in close proximity to each other on the correspondence analysis map in Figure 3 that South African university brands are not distinctly positioned, in social media at least. None of the brands stands out as being particularly more prominent than the others in any one or even a few social media. At the time of writing, this was also practically confirmed by establishing that none of the five institutions had established a formal presence in major social media. For example, while there were "fan pages" on Facebook for the universities, these had been set up informally by current and former students; none of the five institutions was formally "tweeting" on Twitter.

While at first glance these results might seem disappointing, they simply indicate that none of the five university brands is particularly visible in social media, and more importantly, that none of them seems to currently have a concerted strategy for engaging its stakeholders in a particular social media. This means that there are both opportunities for those who manage these brands, and also possible threats to these institutions for taking a laissez fair attitude to social media in these times when social media are coming to dominate the Internet in particular and media in general.

\section{Limitations, managerial implications directions for future research}

This paper descries a methodology for simultaneously mapping a number of competing brands in multidimensional space, based on their visibility in a number of social media. The paper has limitations in that, obviously, it does not claim to be a definitive study of the positioning of all South African university brands in social media, but merely selects a few brands within a limited number of social media, as a means of illustration of a technique. The picture obtained here could well have been very different had different, or more brands been chosen, or if other, or additional social media were chosen. Second, a study such as this provides more of a snapshot in time than an ultimate set of results. It may very well be that if the data had been collected at a different time, perhaps a few months earlier or later and then subjected to an analysis that a very different picture would have emerged. The nature of social media is such that their content evolves continuously. Third, it is unfortunate that in this illustration a clearly distinct picture of the objects studied (the university brands) did not emerge from the content analysis, most likely because none of these brands have a clearly defined social media strategy at present. Had such a picture emerged it would have been possible to speculate more on the differences and similarities between the brands within the various social media. Finally, data from a third party source such as How Sociable has to be taken at face value - if there are weaknesses in the methods How Sociable uses to gather social media data, or errors in the reporting of this, they will obviously be reflected in the results of a study such as this. If there are flaws in How Sociable's methodologies in data gathering, or software glitches at the time the data is gathered, these will obviously be carried over to the analysis, the subsequent maps, and also to the interpretation of the results. While there is no reason to distrust the motivations of the software's producers, How Sociable is a new product that will be subject to the teething pains that many sophisticated analysis tools can suffer.

Nonetheless, a number of managerial implications become apparent from the research conducted here. First, it seems as if the brands considered did not, at the time the data was gathered, have a clearly defined social media strategy. This is currently understandable because social media are a relatively new phenomenon, but the rapid growth of social media means that this laissez faire approach will not be tenable in the future. Astute brand managers will define the social media that they care most about. Then, they will first think seriously about the kind of official presence they wish to establish in these media (for example, an official university fan page on Facebook, regular tweets on Twitter about newsworthy events, and frequent posting of videos concerning the university and its activities (e.g. sporting events, graduation ceremonies, interesting research) on a dedicated YouTube page. Brand managers will also regularly monitor non-official content in social media by regular information scanning of social media sites, and having contingency plans in place that will allow them to act and react appropriately to this. They will also monitor social media content and visibility of brands they regard either as competitors or benchmarks. In this instance, sources of data such as How Sociable.com, and tools such as correspondence analysis that permit the simultaneous picturing of brands in multidimensional space might become invaluable tools. Finally, they will also be able to monitor the effectiveness of social media strategies by using data from sources such as How Sociable to track overall brand visibility, and correspondence analysis maps to determine how a particular strategy had moved the particular brand against competitor brands, and with regard to particular social media. 
Table 3: Correspondence analysis: Eigenvalues and inertia; principal coordinates of rows and columns

\begin{tabular}{|c|c|c|c|c|}
\hline \multicolumn{5}{|c|}{ Eigenvalues and percentages of inertia: } \\
\hline & $\mathrm{F} 1$ & $\mathrm{~F} 2$ & F3 & $\mathrm{F} 4$ \\
\hline Eigenvalue & 0,025 & 0,016 & 0,007 & 0,004 \\
\hline Inertia $(\%)$ & 48,499 & 31,178 & 13,109 & 7,215 \\
\hline Cumulative \% & 48,499 & 79,677 & 92,785 & 100,000 \\
\hline \multicolumn{5}{|c|}{ Principal coordinates (rows): } \\
\hline & $\mathrm{F} 1$ & $\mathrm{~F} 2$ & $\mathrm{~F} 3$ & $\mathrm{~F} 4$ \\
\hline Google PS & $-0,124$ & 0,012 & 0,147 & 0,244 \\
\hline Twitter & 0,021 & 0,323 & $-0,184$ & 0,002 \\
\hline MySpace & 0,181 & 0,003 & $-0,043$ & $-0,074$ \\
\hline Ning & $-0,198$ & $-0,333$ & 0,041 & $-0,075$ \\
\hline Digg & 0,050 & $-0,153$ & $-0,059$ & $-0,118$ \\
\hline Ecademy & 0,171 & $-0,141$ & $-0,197$ & 0,077 \\
\hline Yahoo PS & 0,321 & 0,072 & 0,036 & 0,002 \\
\hline Facebook G & 0,253 & 0,025 & 0,096 & $-0,024$ \\
\hline Facebook P & $-0,138$ & 0,070 & 0,020 & $-0,019$ \\
\hline Google I & 0,158 & $-0,060$ & 0,043 & $-0,001$ \\
\hline Xing & 0,098 & $-0,049$ & $-0,121$ & $-0,145$ \\
\hline Linked In & 0,011 & $-0,105$ & $-0,056$ & 0,031 \\
\hline YouTube V & 0,235 & $-0,022$ & $-0,123$ & 0,081 \\
\hline \multicolumn{5}{|c|}{ Principal coordinates (columns): } \\
\hline & $\mathrm{F} 1$ & $\mathrm{~F} 2$ & $\mathrm{~F} 3$ & $\mathrm{~F} 4$ \\
\hline Cape Town & 0,202 & $-0,075$ & $-0,034$ & $-0,070$ \\
\hline Pretoria & 0,114 & $-0,051$ & 0,036 & 0,105 \\
\hline Rhodes & $-0,019$ & 0,185 & 0,126 & $-0,035$ \\
\hline Stellenbosch & $-0,080$ & 0,143 & $-0,135$ & 0,019 \\
\hline Wits & $-0,236$ & $-0,146$ & 0,019 & $-0,017$ \\
\hline
\end{tabular}

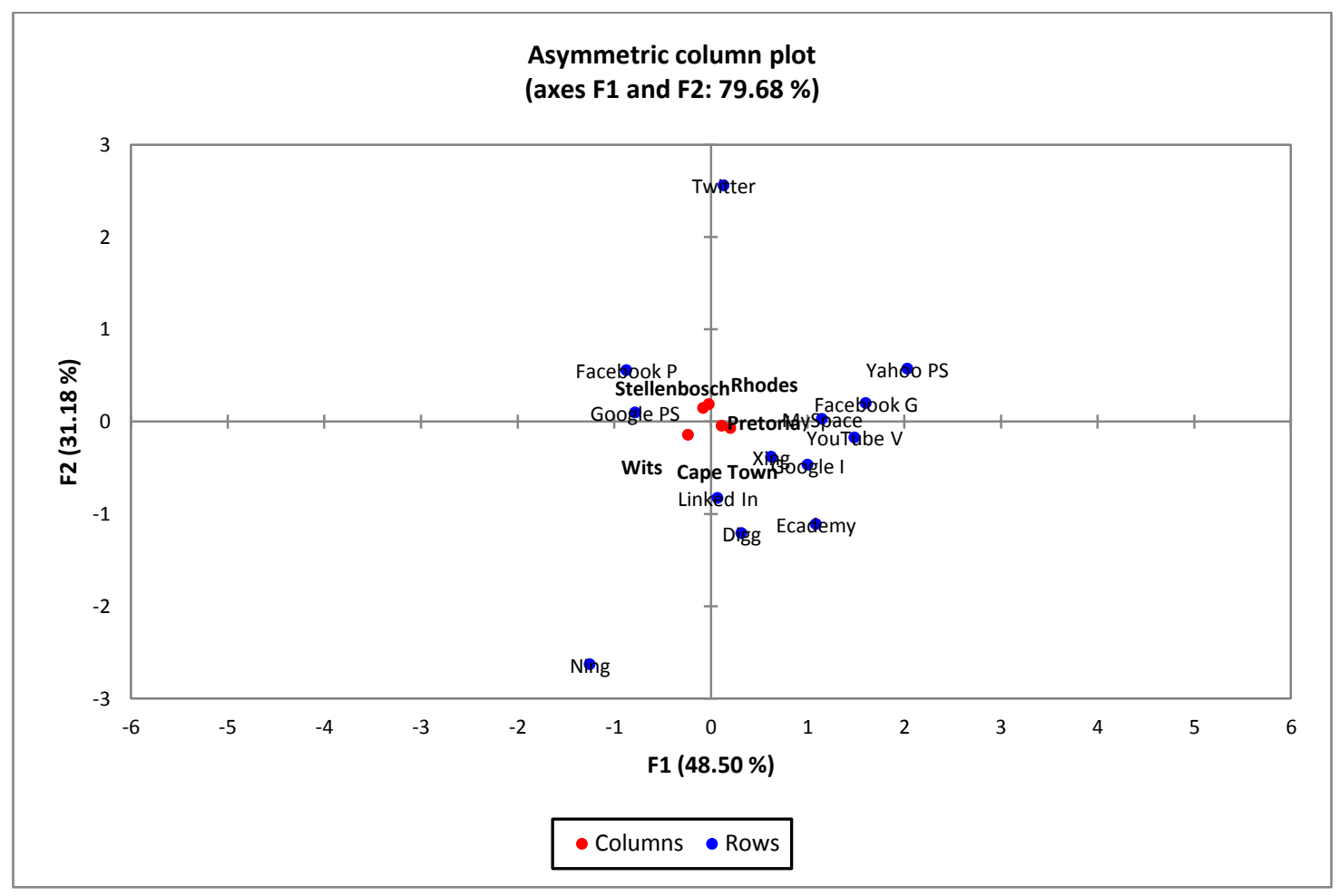

Figure 3. Asymmetric column plot (axes F1 and F2: 79,67 percent) 
Exploratory studies such as those reported in this paper also opens up a stream of further future opportunities for research. First, it would be wise to find ways of confirming the reliability and validity of data gathered by services such as How Sociable. This might be done by consulting and working directly with these service providers in an effort to gain a better understanding of their methodologies and results. It could also be done by closely monitoring the results for a set of brands over a period, and establishing some kind of test-retest pattern to determine reliability. Second, the results of secondary data research such as this could be combined with primary data collection in the target markets of the brands concerned. For example, at a qualitative level, researchers might wish to hold online or face to face focus groups with users of the various social media sites in order to gather in-depth feedback on their involvement in these media. At a more quantitative level, researchers could analyze the text of the interactions that users have concerning their brands in social media. For example, researchers such as Opoku et al. (2007a, 2007b), describe tools that can be used to analyze large amounts of text by means of computerized content analysis that could be employed in this regard. Third, researchers could employ a vast array of tools that are readily available online for social media analysis (many of them free, or at minimal charge, see Barros, 2009) in conjunction with the data from How Sociable, and using tools such as correspondence analysis.

The advent of consumer generated content and its rapid diffusion takes much of the control over messages away from marketers, who find themselves at the mercy of consumers who can create and distribute advertising about their brands (Deighton \& Kornfeld, 2007). This makes the management of brands in an era of social media not only more difficult, but also even more critical than it has been in the past. Brands can take directions in social media that would have been unlikely if not impossible just five years ago. Brand managers will not fully be able to control the destinies of these brands, but at least they should still be part of, and ideally, direct the conversations that occur around their brands. They will need to use every tool at their disposal. We suggest that the approaches followed in the research presented in this paper will be one tool in the brand manager's arsenal that will assist them in this endeavor.

\section{References}

Arington, M. 2010. 'Hitwise says facebook most popular U.S. site'. [online] URL:

http://techcrunch.com/2010/03/15/hitwise-says-facebookmost-popular-u-s-site/.

Barros, S. 2009. 'Know your numbers: 10 free web analytics tools for your website'. [online] URL: http://www.pennolson.com/2009/09/13/know-your-numbers-10-free-webanalytics-tools-for-your-website/.

Bendixen, M. 1996. 'A practical guide to the use of correspondence analysis in marketing research'. [online] URL: www.xlstat.com/ corres3.pdf.

Bendixen, M.T. 1995. 'Composing perceptual mapping using chi-squared trees analysis and correspondence analysis', Journal of Marketing Management, 11(6):571-81.

Berthon, P.R., Pitt, L.F. \& Campbell, C. 2008. 'Ad lib: When customers create the ad', California Management Review, 50(4):6-30.

Bhat, S. \& Reddy, S.K. 1998. 'Symbolic and functional positioning of brands', Journal of Consumer Marketing, 15(1):32-43.

Brogan, C. 2010. Social media 101: tactics and tips to develop your business online. Hoboken: John Wiley and Sons.

Deighton, J. \& Kornfeld, L. 2007. 'Digital interactivity: Unanticipated consequences for markets, marketing, and consumers', Harvard Business School Working Paper, 08017.

Facebook. 2010. 'Facebook press room'. [online] URL: http://www.facebook.com/press/info.php?statistics.

Daily Telegraph. 2008. 'Web could collapse as video demand soars'. [online] URL: www.telegraph.co.uk.

Greenacre, M. 1993. Correspondence analysis in practice. New York: Academic Press.

Hair, J.F., Black, W.C., Babin, B.J., Anderson, R.E. \& Tatham, R.L. 2006. Multivariate data analysis. 6th Edition. Upper Saddle River: Prentice-Hall.

Kaplan A. M. \& Haenlein M. 2010. 'Users of the world, unite! The challenges and opportunities of social media', Business Horizons, 53(1):59-68.

Markwell, J.L. 2010. 'Our visibility score'. [online] URL: http://howsociable.wordpress.com/2008/08/08/ourvisibility-score/.

Neuman, W.L. 2003. Social research methods-qualitative and quantitative approaches. 5th Edition. Boston: Pearson Education.

O’Brien, T.W. 1993. 'Correspondence analysis', Marketing Research, 5(4):54-6.

Opoku, R. A., Abratt, R., Bendixen, M., \& Pitt, L.F. 2007a. 'Communicating brand personality: Are the websites doing the talking for food SME's?', Qualitative Market Research, 10(4):362-374.

Opoku, R.A., Pitt, L.F., \& Abratt, R. 2007b. 'Positioning in cyberspace: Evaluating bestselling authors' online communicated brand personalities using computer-aided content analysis', South African Journal of Business Management, 38(4):21-32.

Steyn, P.G., Van Heerden, G., Pitt, L.F., \& Boshoff, C. 2008. 'Meet the bloggers: Some characteristics of serious bloggers in the Asia-Pacific region, and why PR 
professionals might care about them', Public Relations Quarterly, 52(3):39-44.

Tapscott, D. \& Williams, A.D. 2007. Wikinomics: How mass collaboration changes everything. New York: Penguin.

Yen, Y. 2008. 'YouTube looks for the money clip'. [online] URL:

http://techland.blogs.fortune.cnn.com/2008/03/25/youtubelooks-for-the-money-clip/.

Zarella, D. 2010. The social media marketing book. North Sebastopol: O’Reilly Media. 